\title{
AUTOGAMY AND INBREEDING DEPRESSION IN MOUNTAIN LAUREL, KALMIA LATIFOLIA (ERICACEAE) ${ }^{1}$
}

\author{
BEVERLy RATHCKE ${ }^{2}$ AND LESLIE REAL \\ Department of Biology, University of Michigan, Ann Arbor, Michigan 48109-1048; and \\ Department of Biology, Indiana University, Bloomington, Indiana 47405
}

\begin{abstract}
We compared breeding systems, inbreeding depression, and pollination limitation between two populations of Kalmia latifolia in Virginia and Rhode Island. Plants were autogamous in Virginia but not Rhode Island. Although autogamy with selfing is hypothesized to reduce levels of inbreeding depression, both populations showed similarly high inbreeding depression manifested as reduced fruit set. Autogamy may be uncorrelated with selfing rate because autogamy is not obligate and because geitonogamy is likely. Autogamy in the Virginia population seems most likely to have evolved for reproductive assurance under competition for pollinator service. Fruit set was pollination limited in the Virginia population apparently because bumblebee pollinators were more attracted to a coflowering species, Vaccinium erythrocarpum.
\end{abstract}

The type of breeding system exhibited by a species greatly influences the range of potential matings available to individuals and is a major determinant of patterns of genetic variation and evolution within populations. Autogamy (i.e., the ability of a flower to self-fertilize in the absence of pollinators) is common in many plant taxa and has evolved independently many times from outcrossing, self-incompatible species (Wyatt, 1983; Mulcahy, 1984; Webb, 1984). Levels of autogamy have been found to be negatively correlated with outcrossing rates in Gilia achilleifolia and have been used to infer breeding systems and selfing rates (Schoen, 1982; Wyatt, 1988).

If autogamous plants have increased selfing rates, they are expected to exhibit low inbreeding depression because habitual selfing should purge deleterious recessive genes from the population over time (Schemske and Lande, 1985; Charlesworth and Charlesworth, 1987). However, more recent theoretical studies suggest that habitual selfers can exhibit high inbreeding depression (Holsinger, 1988; Charlesworth, Morgan, and Charlesworth, 1990). The actual relationship between selfing and inbreeding depression in natural populations is poorly understood because surprisingly few studies have been done, and these results are often contradictory (Charlesworth and Charlesworth, 1987; Levin, 1989; Johnston, 1992). In addition, most comparative studies of autogamy have been made between different species rather than within species (Wyatt, 1983, 1988; but see Schoen, 1982), and few data exist on between-population variation in autogamy and inbreeding depression for natural plant populations.

In this paper we document between-population variation in autogamy in mountain laurel (Kalmia latifolia L.; Ericaceae) growing in Virginia and Rhode Island, and we relate this variation to levels of inbreeding depression expressed as reduced fruit set. This maternal fecundity component of inbreeding depression provides a minimum estimate of inbreeding depression. Although reduced fruit set can also include effects of self-incompatibility (Barrett, 1988; Manasse and Pinney, 1991), this is unlikely for

\footnotetext{
${ }^{1}$ Received for publication 10 December 1991; revision accepted 13 October 1992.

The authors thank J. Brunet for discussions and helpful comments This research was supported by NSF grants G-DEB78-24678 and BSR8500203.

${ }^{2}$ Author for correspondence (FAX: 313-747-0884).
}

Kalmia latifolia. Jaynes (1968) found no evidence of stylar inhibition of self- vs. cross-pollen tube growth nor of an s-allele system of incompatibility.

We also discuss some possible evolutionary explanations for the evolution of autogamy in the Virginia population. Many factors have been proposed to explain the evolution of autogamy, including reproductive assurance, reproductive isolation, and the retention of locally adapted gene complexes (Jain, 1976; Wyatt, 1983; Mulcahy, 1984). We examine evidence for these hypotheses based on this and previous studies of the pollination ecology of Kalmia latifolia (Rathcke, 1988a, b; Real and Rathcke, 1991).

\section{MATERIALS AND METHODS}

Study species and sites - Mountain laurel (Kalmia latifolia $\mathrm{L}$.: Ericaceae) is a common evergreen shrub that grows in ericaceous heath communities in mountainous regions of eastern North America and in the understory of forests in eastern coastal areas (Jaynes, 1975). An individual shrub commonly has hundreds of inflorescences (corymbs), each with 50-300 flowers, and can have thousands of flowers in anthesis at the same time. Flowers are tubular with white or pink fused petals and are herkogamous, i.e., the anthers and stigmas are spatially separated. Anthers are inserted in pockets in the corolla. When a visitor touches the stamen filament, the anthers spring up and cast pollen over the visitor. However, the anthers will release without a visitor at the end of floral life. The only floral visitors to Kalmia latifolia in our two study sites were bumblebees. Fruits are dehiscent capsules with hundreds of tiny, wind-dispersed seeds.

Kalmia latifolia was studied in two geographic sites: a southern Appalachian heath bald at Bald Knob on Salt Pond Mountain in Virginia near the Mountain Lake Biological Station, University of Virginia (described in real and Rathcke, 1988 and 1991) and a coastal wooded swamp in The Great Swamp Management Area near Kingston, Rhode Island (described in Rathcke, 1988a, b). In Rhode Island, shrubs were studied in two local sites: a cut-over, sunny field site with no tree canopy and a shaded forest site with a sparse tree canopy.

Pollination methods - To test for autogamy and inbreeding depression, pollinators were excluded by bagging 
TABLE 1. Autogamy and inbreeding depression in Kalmia latifolia in $V i r g i n i a$ and Rhode Island. Mean fruits per flower (SD, number of individuals) are shown for different pollination treatments. Inbreeding depression is estimated as I - (fruit set by self-pollen/fruit set by cross-pollen)

\begin{tabular}{lll}
\hline \hline & \multicolumn{1}{c}{ Virginia } & \multicolumn{1}{c}{ Rhode Island } \\
\hline No pollination & $0.17(0.13,5) \mathrm{A}^{\mathrm{a}}$ & $0.01(0.00,5) \mathrm{A}^{\mathrm{a}}$ \\
Self-pollen & $0.18(0.21,7) \mathrm{A}$ & $0.15(0.21,5) \mathrm{B}$ \\
Cross-pollen & $0.80(0.13,10) \mathrm{B}$ & $0.65(0.26,8) \mathrm{C}$ \\
Inbreeding depression & 0.78 & 0.77 \\
\hline
\end{tabular}

a Column means with different capital letters are significantly different $(P<0.05)$ by $t$-tests using arcsine-transformed data.

budded inflorescences with bridal veiling. Three inflorescences on each individual shrub were bagged, and each inflorescence was randomly assigned to one of three pollination treatments: no hand-pollination, hand-pollination with self-pollen from the same individual, or handpollination with cross-pollen from at least four distant individuals $(>5 \mathrm{~m})$. Flowers were pollinated every day they were open with pollen transferred from glass slides to the stigmas. Fruits produced by these inflorescences were counted in August when they were full-sized and after fruit abortion had occurred (see Rathcke, 1988b). Fruit set was calculated as the ratio of fruits to flower buds.

Inbreeding depression was estimated as the maternal fecundity component of inbreeding depression (IBD) as follows: IBD $=1-$ (fruit set in selfed flower/fruit set in outcrossed flowers) (Holsinger, 1988).

To determine whether current fruit set was pollination limited, fruit set was compared between inflorescences that were exposed to natural pollination (open) and inflorescences that were augmented with cross-pollen from at least four distant individuals. These data are from two earlier papers (Rathcke, 1988b; Real and Rathcke, 1991).

\section{RESULTS}

Autogamy is apparent in the Virginia population of Kalmia latifolia but not in the Rhode Island population (Table 1). In the Virginia population, fruit set with pollinator exclusion and no hand-pollination was equal to

TABle 2. Pollination limitation in Kalmia latifolia in Virginia and Rhode Island. Mean fruits per flower (SD, number of individuals) are shown for naturally pollinated flowers and for flowers augmented with cross-pollen

\begin{tabular}{ccc}
\hline \hline & \multicolumn{2}{c}{ Fruits per flower } \\
\cline { 2 - 3 } $\begin{array}{c}\text { Virginia } \\
1985\end{array}$ & $0.37(0.16,28) \mathrm{A}^{\mathrm{a}}$ & $0.48(0.23,28) \mathrm{B}$ \\
Rhode Island field site & \\
1981 & $0.59(0.14,8) \mathrm{A}$ & $0.55(0.19,13) \mathrm{A}$ \\
1982 & $0.68(0.24,10) \mathrm{A}$ & $0.69(0.18,10) \mathrm{A}$ \\
Rhode Island forest site & \\
1981 & $0.19(0.16,18) \mathrm{A}$ & $0.66(0.19,27) \mathrm{B}$
\end{tabular}

a In a row, means with different capital letters are significantly different $(P<0.05)$ by paired $t$-tests for the Virginia data and by $t$-tests on arcsine-transformed data for the Rhode Island data. Data from Rathcke (1988b) and Real and Rathcke (1991). that produced by hand-pollination with self-pollen $(17 \%$ vs. $18 \%$ ) (Table 1). In the Rhode Island population, fruit set under no pollination was only $1 \%$. This $1 \%$ was caused by a single fruit and probably reflects pollen contamination because fruit set was never observed in 60 additional bagged inflorescences on 20 other individual shrubs in other years.

Despite the difference in autogamy between these two populations, the maternal fecundity component of inbreeding depression was similarly high in both populations $(0.78$ in Virginia and 0.77 in Rhode Island) (Table 1 ). The self-pollen treatment showed significantly lower fruit set than the cross-pollen treatment in both populations.

Previous results showed that current fruit set was pollination limited in the Virginia population. Fruit set was significantly greater for inflorescences augmented with cross-pollen than for naturally pollinated (open) inflorescences (paired $t$-tests, $P<0.05, \mathrm{t}=2.196, \mathrm{df}=26$ ) (Table 2; Real and Rathcke, 1991). In addition, fruit set was greater under natural pollination than for either no pollination or augmented self-pollen suggesting that some outcrossing occurred in the open inflorescences (Tables $1,2)$. In the Rhode Island population, current fruit set was not pollination limited in the sunny field site but was pollination limited in the shaded forest site where resources may be low for both nectar and fruit production (Table 2; Rathcke, 1988b).

\section{DISCUSSION}

The occurrence of autogamy in the Virginia population was unexpected because Kalmia latifolia is considered to be a nonselfing species (Fryxell, 1957; Jaynes, 1975). Between-population variation in the breeding system has not been previously reported despite many horticultural breeding studies (Jaynes, 1975). The lack of autogamy seen in the Rhode Island population is probably more typical for the species.

Although the two populations differed in autogamy, they both showed similarly high levels of inbreeding depression $(>75 \%)$ manifested as reduced fruit set, which is a minimum estimate. Jaynes (1968) found that inbreeding depression was also manifested as a nearly twofold reduction in vigor (height growth) and in lower seedling survival, as well as in reduced seed set, in 11 different populations of Kalmia latifolia. Inbreeding depression is likely to be significant for overall fertility in this species and should be a significant selective force against selfing (Shields, 1982).

This lack of correlation between autogamy and inbreeding depression may support the contention that selfing rates and inbreeding depression need not be correlated (Holsinger, 1988; Charlesworth, Morgan, and Charlesworth, 1990). However, this interpretation assumes that autogamy is a good estimator of selfing as was seen in Gilia achilleifolia (Schoen, 1982), but this may not be true in Kalmia latifolia for two major reasons. First, selfing through autogamy may be rare in the Virginia population because autodeposition of pollen occurs only at the end of floral life as reproductive assurance if a flower has not been visited; hence, flowers may be mostly cross-pollinated. In fact, selfing alone cannot account for the high 
level of fruit set seen under natural pollination. Second, despite the possible low level of autogamous selfing, actual selfing rates could be high and similar in both populations because of geitonogamy (pollination between flowers within an individual). Pollinating bumblebees commonly visit hundreds of flowers before leaving a shrub, and geitonogamy could contribute significantly to the selfing rates in both populations (e.g., Hessing, 1988; Johnston, 1992). As a result, both populations could experience similar levels of selfing through geitonogamy, or, more likely, geitonogamous selfing may covary with autogamy. In Rhode Island, pollinator visits are frequent in sunny sites, and geitonogamous selfing may be important (Rathcke, 1988 b). In Virginia, bumblebee visits are relatively rare (Real and Rathcke, 1991) and autogamous selfing could be more important than geitonogamous selfing. If selfing is actually high in one or in both populations, this would contradict the conventional idea that high inbreeding depression suggests high outcrossing rates (Schemske and Lande, 1985) and support the recent contention that selfing rates and inbreeding depression need not be correlated (Charlesworth and Charlesworth, 1987; Holsinger, 1988). If selfing is actually low in both populations, this would support conventional theory. These different arguments can only be resolved through direct measurements of both autogamous and geitonogamous selfing rates.

Determining the contributions of autogamous vs. geitonogamous selfing to selfing rates will be important if we are to understand the genetic basis of selfing and the evolution of plant breeding systems. For example, autogamy is commonly associated with floral features, such as stigma exertion, which have been shown to have genetic bases (Schoen, 1982; Wyatt, 1988). On the other hand, geitonogamy is commonly associated with such plant features as flower number or flowering phenology, which are often highly influenced by environmental factors so that phenotypic variation may be less responsive to selection (Rathcke, 1992).

Given that autogamy can occur despite high inbreeding depression in Kalmia latifolia, the question arises as to why most populations do not have this ability to selffertilize without a pollinator. One possible reason is that autogamy could be selected against if discounting rates are high (i.e., if selfing significantly reduces the chance to outcross) (Holsinger, 1988), but this seem unlikely for Kalmia latifolia. Autogamous selfing occurs only at the end of floral life when outcrossing has failed. If discounting rates are low, Lloyd (1979) argues that the ability to selfpollinate after chances of cross-pollination have passed should always be favored for reproductive assurance unless seed set is never pollination limited. If so, this suggests that pollination limitation is relatively rare or weak in most populations of Kalmia latifolia and supports the hypothesis that pollination limitation in the Virginia population is a major factor in the evolution of autogamy.

Because fruit set is pollination limited in the Virginia population, selection for reproductive assurance seems to be the most plausible explanation for the evolution of autogamy in this species. The hypothesis based on selection for reproductive isolation is not applicable because Kalmia latifolia has no congeners in Virginia where it is autogamous whereas it has one congener, $K$. angustifolia, in Rhode Island where it is not autogamous. Also, $K$. latifolia pollen will not grow on the stigmas of congeners (Jaynes, 1971). Natural hybrids of Kalmia species are unknown and species are reproductively isolated (Jaynes, 1971). The hypothesis based on selection for the maintenance of adaptive gene complexes is also inapplicable to Kalmia latifolia because inbreeding depression is high and selfing is not obligate.

Selection for reproductive assurance under pollination uncertainty is the most common explanation for autogamy in other plant species (Wyatt, 1988; but see Arroyo and Squeo, 1990), but for most of these species, the pollination uncertainty is attributed to a paucity of pollinators caused by severe environmental conditions (Arroyo, Armesto, and Primack, 1985; Wyatt, 1988; Berry and Calvo, 1989). For Kalmia latifolia, pollination limitation is more likely caused by competition for pollinator service. Bumblebees seldom visited Kalmia latifolia because they were more attracted to a coflowering species, Vaccinium erythrocarpum (Real and Rathcke, 1991; unpublished data). Kalmia latifolia may be one of the relatively few examples where competition for pollinator service appears to be important in selecting for reproductive assurance through autogamy (Levin, 1972; Wyatt, 1983).

\section{LITERATURE CITED}

Arroyo, M. T. K., J. Armesto, and R. Primack. 1985. Community studies in pollination ecology in the high temperate Andes of central Chile. II. Effect of temperature on visitation rates and pollination possibilities. Plant Systematics and Evolution 149: 187-203.

$\longrightarrow$, AND F. SQUEO. 1990. Relationship between plant breeding systems and pollination. In $\mathrm{S}$. Kawano [ed.], Biological approaches and evolutionary trends in plants, 205-277. Academic Press, San Diego, CA.

BARretT, S. C. H. 1988. The evolution, maintenance, and loss of selfincompatibility systems. In J. Lovett Doust and L. Lovett Doust [eds.], Plant reproductive biology: patterns and strategies, 98-124. Oxford University Press, New York, NY.

BERRY, P. E., AND R. N. Calvo. 1989. Wind pollination, self-incompatibility, and altitudinal shifts in pollination systems in the High Andean genus Espeletia (Asteraceae). American Journal of Botany 76: 1602-1616.

Charlesworth, D., and B. Charlesworth. 1987. Inbreeding depression and its evolutionary consequences. Annual Review of Ecology and Systematics 18: 237-268.

- , M. T. Morgan, AND B. Charlesworth. 1990. Inbreeding depression, genetic load, and the evolution of outcrossing rates in a multilocus system with no linkage. Evolution 44: 1469-1489.

FrYXELL, P. A. 1957. Mode of reproduction in higher plants. Botanical Review 23: 135-233.

Hessing, M. B. 1988. Geitonogamous pollination and its consequences in Geranium caespitosum. American Journal of Botany 75: 13241333.

Holsinger, K. E. 1988. Inbreeding depression doesn't matter: the genetic basis of mating-system evolution. Evolution 42: 1235-1244.

JaIN, S. K. 1976. The evolution of inbreeding in plants. Annual Review of Ecology and Systematics 7: 469-495.

JAYNES, R. A. 1968. Self incompatibility and inbreeding depression in three laurel (Kalmia) species. American Society for Horticultural Science 93: 618-622.

1971. The Kalmias and their hybrids. Quarterly Bulletin of the American Rhododendron Society 25: 160-164.

- 1975. The laurel book. Hafner Press, New York, NY.

JoHNSTON, M.O. 1992. Effects of cross and self-fertilization on progeny fitness in Lobelia cardinalis and L. silphilitica. Evolution 46: 688702.

LeviN, D. A. 1972. Competition for pollinator service: a stimulus for the development of autogamy. Evolution 26: 668-674. 
1989. Inbreeding depression in partially self-fertilizing Phlox. Evolution 43: 1417-1423.

LLOYD, D. G. 1979. Some reproductive factors affecting the selection of self-fertilization in plants. American Naturalist 113: 67-79.

Manasse, R. S., AND K. PinNey. 1991. Limits to reproductive success in a partially self-incompatible herb: fecundity depression at serial life-cycle stages. Evolution 45: 712-720.

MulCAHY, D. L. 1984. The relationship between self-incompatibility, pseudo-compatibility, and self-compatibility. In W. F. Grant [ed.], Plant biosystematics, 229-235. Academic Press, New York, NY.

RATHCKE, B. 1988a. Flowering phenologies in a shrub community: competition and constraints. Journal of Ecology 76: 975-994.

- 1988b. Interactions for pollination among coflowering shrubs. Ecology 69: 446-457.

- 1992. Nectar distributions, pollinator behavior, and plant reproductive success. In M. D. Hunter, T. Ohguishi, and P. W. Price [eds.], Effects of resource distribution on animal-plant interactions, 113-138. Academic Press, New York, NY.

ReAl, L., AND B. RATHCKE. 1988. Patterns of individual variability in floral resources. Ecology 69: 728-735.
, AND -1991 . Individual variation in nectar production
and its effects on plant fitness in the mountain laurel (Kalmia latifolia). Ecology 72: 149-155.

SCHEMSKe, D. W., AND R. LANDE. 1985. The evolution of self-fertilization and inbreeding depression in plants. I. Genetic models. Evolution 39: 24-40.

SCHOEN, D. J. 1982. The breeding system of Gilia achilleifolia: variation in floral characteristics and outcrossing rate. Evolution 36: 352-360.

SHIELDS, W. M. 1982. Philopatry, inbreeding and the evolution of sex. State University of New York Press, Albany, NY.

WeBB, C. J. 1984. Constraints on the evolution of plant breeding systems and their reference to systematics. In W. F. Grant [ed.], Plant biosystematics, 249-270. Academic Press, New York, NY.

WYATT, R. 1983. Pollinator-plant interactions and the evolution of breeding systems. In L. Real [ed.], Pollination biology, 51-96. Academic Press, New York, NY.

. 1988. Phylogenetic aspects of the evolution of self-pollination. In L. D. Gottlieb and S. K. Jain [eds.], Plant evolutionary biology, 109-131. Chapman and Hall, London, UK. 